\title{
REFLEXIONES SOBRE LA IRRACIONALIDAD DE LA PENA DE PRISIÓN EN MÉXICO
}

\author{
Reflections on the irrationality of the prison penalty in Mexico
}

Arturo Villareal Palos

Sumario:

Introducción 1. Breve excurso sobre la función de la pena 2. Los principios reguladores o limitadores del derecho penal 3. La situación de la pena máxima de prisión en México 4. Situación de la pena de prisión en Europa 5. Las penas de prisión en el Estatuto de Roma de la Corte Penal Internacional 6. Conclusiones

Resumen: El presente artículo hace un análisis sobre las excesivas e irracionales penas de prisión existentes en México, que pueden llegar a ser vitalicias o rondar hasta los 140 años de prisión. El autor hace hincapié en su inconstitucionalidad a la luz de los principios de proporcionalidad y reinserción social de la pena y hace algunas propuestas para que la pena máxima de prisión pueda ser compatible con dichos principios.

Palabras clave: Inconstitucionalidad, penas vitalicias, penas muy largas de prisión

Abstract: This paper analyzes the excessive and irrational prison sentences in Mexico, which can be lifelong or up to 140 years in prison. The author emphasizes his unconstitutionality acording with the principles of proportionality and social reintegration of the penalty and makes some proposals so that the maximum prison sentence can be compatible with these principles.

Keywords: Unconstitutionality, life sentences, very long prison sentences

\section{Introducción}

El presente trabajo contiene algunas reflexiones sobre la irracionalidad de la pena de prisión en México, que puede llegar a ser vitalicia y, en algunos casos, rondar hasta los 140 años de prisión, lo que abiertamente contraviene los principios de proporcionalidad y reinserción social de la pena previstos en la Constitución de la República y, además, evidencia una clara aplicación de la teoría de la prevención general negativa de la pena a la hora de legislar (creencia exagerada en que el aumento de la magnitud de la sanciónacarreará una inmediata disuasión del probable infractor) y de la teoría de la prevención especial negativa en la fase de ejecución, pues lo que se busca no es reinsertar socialmente al delincuente, sino segregarlo del cuerpo social.

A los efectos anteriores, el trabajo proporciona un marco teórico y referencial, aludiendo, en primer término, a las diferentes teorías sobre la función de la pena, para luego pasar a analizar los principios reguladores o limitadores del derecho penal, entre los que se encuentran los

\footnotetext{
* Doctor en Derecho, Profesor titular de la Universidad de Guadalajara.
} 
principios de proporcionalidad y reinserción social de la pena, que han sido reconocidos por nuestra carta suprema.

Se continúa con el examen de la pena de prisión vitalicia y las penas muy largas de prisión en México y, a fin de tener un marco comparativo, se alude a la situación de las penas máximas de prisión en Europa y en el Estatuto de Roma de la Corte Penal Internacional, que como sabemos sanciona los crímenes más graves para la humanidad. Asimismo, se alude a la prisión permanente revisable que se aplica en algunos países europeos y en la propia justicia penal internacional.

El artículo concluye con un balance de la situación y propone, en el mediano plazo, adoptar una ley general penal que establezca un tope máximo de 30 años para la pena de prisión en México, lo que la haría compatible con los principios constitucionales de proporcionalidad y reinserción social de la pena y, para el corto plazo, se rescata la propuesta de la Comisión Nacional de los Derechos Humanos, para establecer un programa de prisión permanentemente revisable para aquellas personas sentenciadas a prisión vitalicia y con condenas superiores a los 30 años, lo que podría equilibrar la situación, en espera de futuras reformas legales.

\section{Breve excurso sobre la función de la pena}

Como sabemos, la cuestión del fin de la pena, se haya vinculada, históricamente, con las tres teorías que han pretendido explicarla: las teorías absolutas (función retributiva), las teorías relativas (función de prevención) y las teorías de la unión (eclécticas).

Las teorías absolutas atribuyen a la pena una función exclusivamente retributiva, la cual se agota en el castigo del hecho cometido. Esta fue la posición defendida, desde perspectivas diversas, por Kant y Hegel, aunque en términos estrictos no ha sido seguida ni por la ciencia penal ni por la legislación, pues aun desde esta posición, subsidiariamente también se han atribuido a la pena funciones de prevención ${ }^{1}$.

Para las teorías relativas (que se denominan así en razón de que las necesidades de prevención son relativas y circunstanciales) ${ }^{2}$, la pena sólo puede servir a la prevención de futuros delitos, ya sea por la vía de la prevención general (positiva o negativa) o de la prevención especial (positiva o negativa), según la corriente que se adopte.

Para la teoría de la prevención general negativa, siguiendo el modelo propuesto por Feuerbach, la pena sirve como amenaza (conminación penal) dirigida a todos los ciudadanos para evitar que delincan; es decir, opera como una coacción psicológica a partir de la tipificación penal $^{3}$. Se critica a la prevención general negativa, ya por suponer una mera función utilitaria o utilitarista del delincuente ${ }^{4}$ o bien porque los estudios empíricos demuestran que el cálculo de la criminalidad, en su mayoría, no está determinado por la cuantía de la pena, sino por la menor o mayor posibilidad de ser descubierto 5 . Sin embargo, la crítica más extendida en contra

\footnotetext{
1 Sobre el particular véase: Villarreal Palos, Arturo, (1987), “La Función de la Pena”, en: Criminalia, Órgano de la Academia Mexicana de Ciencias Penales, México, D. F., enero-diciembre, núms. 1-12, Editorial Porrúa, pp. 185 y 186.

2 Sobre las teorías relativas, vid. Mir Puig, Santiago (2006), Derecho Penal. Parte General, 8 a edición, Barcelona, España, Editorial Reppertor, p. 81.

3 Vid. Villarreal Palos, op. cit. nota 1.

${ }^{4}$ Vid. Zaffaroni, Eugenio Raúl, Alagia, Alejandro y Slokar, Alejandro (200o), Derecho Penal: Parte General, Buenos Aires, Argentina, Editorial Ediar, p. 54.

5 Vid. Roxin, Claus (1994), Derecho Penal: Parte General. “Tomo I. Fundamentos. La Estructura de la Teoría del Delito", Traducción de la $2^{a}$ edición alemana y notas por Diego-Manuel LuzónPeña, Miguel Díaz y García Conlledo y Javier de Vicente Remesal (200o), Madrid, Editorial Civitas p. 91.
} 
de la prevención general negativa, reside en sus excesos, pues la creencia exagerada en el poder disuasorio de la pena, inexorablemente conduce al terror estatal ${ }^{6}$.

Por ello, en los últimos tiempos ha tomado impulso la teoría de la prevención general positiva (o integradora), que - en palabras de Silva Sánchez- buscaría proyectarse más bien sobre el fuero interno de los ciudadanos, a fin de generar una actitud de convencimiento o de fidelidad al derecho, lo que se entiende como más eficaz que la mera intimidación. Günther Jakobs, uno de los principales propugnadores de esta teoría, entiende que la prevención general positiva se efectúa a través de la punición estatal y tiene tres efectos fundamentales que son: a) ejercitar en la confianza hacia la norma, b) ejercitar en la fidelidad al derecho y c) ejercitar en la aceptación de las consecuencias del quebramiento de la norma, todo lo cual, según Jakobs, puede resumirse como un ejercicio en el reconocimiento de la norma ${ }^{8}$. Desde la perspectiva de Claus Roxin, en la prevención general positiva es posible distinguir tres fines y efectos distintos: a) un efecto de aprendizaje motivado social-pedagógicamente; b) un ejercicio en la confianza del derecho que surge cuando el ciudadano ve que el derecho se aplica y, finalmente, c) un efecto de pacificación que se produce cuando la conciencia jurídica general se tranquiliza, en virtud de la sanción, sobre el quebrantamiento de la ley y considera solucionado el conflicto con el autor ${ }^{9}$.

Por su parte, la teoría de la prevención especial negativa, entiende que esta actúa sobre el delincuente, ya sea para neutralizarlo o eliminarlo del cuerpo social, mientras que la prevención especial positiva buscar su resocialización o reinserción social ${ }^{10}$.

Las teorías de la unión (eclécticas), consideran que la pena cumple en efecto una función retributiva, pero que se ve complementada por fines preventivos. Algunos ven en la retribución el fundamento de la pena y conceden a la prevención fines secundarios, mientras que otros consideran que el fundamento de la pena es la defensa de la sociedad (protección de bienes jurídicos) y que la retribución es sólo el límite de la prevención. Sin embargo, es característico de esta posición el que un fin quede subordinado al otro ${ }^{11}$.

Muñoz Conde apunta que las teorías de la unión aparecen en la historia del derecho penal como una solución de compromiso entre dos bandos irreconciliables: los partidarios de las teorías absolutas y los partidarios de las teorías relativas, pero que, como toda solución de compromiso, desemboca en un eclecticismo que, queriendo contentar a todos, no satisface totalmente a nadie ${ }^{12}$.

De aquí la aparición de teorías alternativas sobre la función de la pena, cuya característica fundamental no es la subordinación de polos contrapuestos, sino la coordinación entre las diversas funciones que la pena cumple ${ }^{13}$.

Una de las aportaciones más importantes en este sentido, lo constituye la teoría unificadora-dialéctica de la pena de Claus Roxin, según la cual el Derecho Penal se enfrenta al indivi-

\footnotetext{
${ }^{6}$ Ibídem, p. 93.

7 Vid. Silva Sánchez, Jesús-María (1992), Aproximación al Derecho Penal Contemporáneo, Barcelona, España, José María Bosch Editor, pp. 229 y ss.

${ }^{8}$ Vid. Jаковs, Günther (1991), Derecho Penal: Parte General. Fundamentos y Teoría de la Imputación, Traducción de la $2^{a}$ edición alemana por Joaquín Cuello Contreras y José Luis Serrano González de Murillo (1997), Madrid, Marcial Pons, Ediciones Jurídicas, pp. 18 y 26 a 29.

9 Vid. Roxin, op. cit. nota 5, pp. 91 y 92.

${ }^{10}$ Por todos, vid. Zaffaroni, Alagia y Slokar, op. cit. nota 4, pp. 54 y 59 a 61.

${ }^{11}$ Cfr. Muñoz Conde, Introducción al estudio del Derecho penal, España, Bosh Casa Editorial, pp. 87 a 89.

${ }^{12}$ Cfr. Muñoz Conde, "El Derecho penal en tiempos de cólera", en: Nuñez Paz, Miguel Ángel (editor y coordinador) Un derecho penal coprometido. Libro homenaje al prof. Dr. D. Gerardo Landrove Díaz, Valencia, España, Editorial Tirant lo Blanch, p. 35.

${ }^{13}$ Sobre estas teorías, en general, vid. Villarreal Palos, op. cit. nota 1, pp. 188 y ss.
} 
duo de tres maneras: amenazando con, imponiendo y ejecutando penas, y que esas tres esferas de actividad estatal necesitan de justificación cada una por separado. De aquí se desprende la idea,explicitada por el autor, de que la pena no cumple una sola función (como lo subrayan las teorías monistas) o que tiene funciones que se subordinan (según el planteo de las teorías de la unión); más bien se trata de la afirmación de que la pena cumple funciones diversas, según sea el momento en que se aplique; así y según la tesis de Roxin, al momento de la conminación penal, será decisiva la idea preventivo-general; al tiempo de la imposición y medición, se refuerza dicha prevención y llegado el caso de la ejecución, la pena se orienta a la prevención especial ${ }^{14}$.

Ahora bien, explicitados los diversos planteamientos en torno a la función de la pena, a los efectos del presente trabajo, habremos de prestar especial atención a las teorías de la prevención general negativa y de la prevención especial negativa, que, de manera más que evidente, subyacen en la configuración de la pena de prisión en nuestro país.

\section{Los principios reguladores o limitadores del derecho penal}

Continuando con la construcción del marco teórico aplicable a este trabajo, debemos recordar que el ius puniendi o derecho de castigar en un Estado democrático de derecho, está sujeto a una serie de principios que lo guían o modelan y que a la vez constituyen los límites que deben respetar el legislador y los demás órganos encargados de aplicar las leyes penales.

El primero de estos principios, a su vez el más antiguo, es el principio de legalidad, que se enuncia bajo los postulados de no hay crimen sin ley (nullum crime sine lege) y no hay pena sin ley (nulla poena sine lege) y que en nuestro país se recoge en el artículo 14 Constitucional.

Las consecuencias directas de este principio según nos recuerda Roxin, son la prohibición de la analogía, la prohibición del derecho consuetudinario para fundamentar y agravar la pena, la prohibición de la retroactividad y la prohibición de leyes penales y penas indeterminadas ${ }^{15}$.

Otros principios, según destaca Mir Puig, son el principio de utilidad de la intervención penal; el principio de subsidiariedad y carácter fragmentario del Derecho penal o principio de intervención mínima; el principio de exclusiva protección de bienes jurídicos; el principio de humanidad de las penas; el principio de culpabilidad; el principio de proporcionalidad y el principio de resocialización ${ }^{16}$.

Para los fines de este estudio, es necesario profundizar en los principios de proporcionalidad y de resocialización, que en nuestro medio se denomina ahora principio de reinserción social.

El principio de proporcionalidad señala que la gravedad de la pena debe ser proporcional al hecho cometido, para lo cual debe ponderarse la importancia social del hecho ${ }^{17}$. Asimismo, este principio obliga a jerarquizar las lesiones y a establecer un grado de mínima coherencia entre

\footnotetext{
${ }^{14}$ Cfr. Roxin, Claus (1976), “Sentido y Límites de la Pena Estatal”, en: Problemas Básicos del Derecho Penal. Trad. del alemán y notas por Diego Manuel Luzón Peña. Madrid, Editorial Reus, pp. 20 a 35. Vid. también Roxin, op. cit., nota 5, pp. 95 y 97.

${ }^{15}$ Cfr. Roxin, op. cit. nota 5, pp. 137 a 140.

${ }^{16}$ Vid. Mir Puig, op. cit. nota 2, pp. 116 a 129.

${ }^{17}$ Ibídem, pp. 127 y 128.
} 
las magnitudes de penas asociadas a cada conflicto criminalizado, no pudiendo tolerar, por ejemplo, que las lesiones a la propiedad tengan mayor pena que las lesiones a la vida ${ }^{18}$.

Este principio se encuentra establecido en el artículo 22 Constitucional, primer párrafo, el cual señala que toda pena deberá ser proporcional al delito que sancione y al bien jurídico afectado.

Este principio fue introducido por la reforma constitucional publicada en el Diario Oficial de la Federación el 18 de junio de 2008 y, de acuerdo a los Dictámenes de las Cámaras de Senadores $^{19}$ y Diputados ${ }^{20}$, tuvo por objeto que el legislador secundario, al momento de determinar las penas, buscara la congruencia entre la sanción y la importancia del bien jurídico que se tutela y así, entre mayor fuese la afectación, la pena debería ser mayor, y viceversa.

Asimismo, el principio de proporcionalidad se contempla respecto de las medidas imponibles a los adolescentes, al señalarse, en el artículo 18 Constitucional, sexto párrafo, que estas deberán ser proporcionales a la conducta realizada.

En cuanto al principio de reinserción social, este se enuncia en el referido artículo 18 Constitucional, párrafos segundo y sexto, los cuales señalan que el sistema penitenciario se organizará sobre la base del respeto a los derechos humanos, del trabajo, la capacitación para el mismo, la educación, la salud y el deporte como medios para lograr la reinserción del sentenciado a la sociedad y procurar que no vuelva a delinquir y que, tratándose delas medidas que se les impongan a los adolescentes, estas tendrán como fin su reintegración social y familiar, así como el pleno desarrollo de su persona y capacidades.

Como vemos, acorde al texto constitucional, el fin que a la pena se asigna, tanto en adultos como en adolescentes (medidas, en el caso de estos últimos), es el de la reinserción o reintegración social, lo que supone una apuesta por la teoría de la prevención especial positiva.

\section{La situación de la pena máxima de prisión en México}

Recientemente, la Comisión Nacional de los Derechos Humanos (CNDH) emitió un pronunciamiento sobre la racionalización de la pena de prisión en nuestro país y en donde hace un análisis muy completo sobre la pena de prisión vitalicia y las penas de muy larga duración.

Así y de acuerdo con el referido informe, los delitos castigados con penas de larga duración en México son básicamente de tres tipos:

1. Los sancionados a partir de un marco punitivo específico que resultan tan elevadas que pueden llegar a considerarse una cadena perpetua encubierta, como es el caso de los relacionados con el secuestro o delincuencia organizada.

2. Las sentencias que han optado por condenar con pena vitalicia, por encontrarse dentro del catálogo de penas (como es el caso del Estado de México, Chihuahua, Puebla, Quintana Roo y Veracruz).

\footnotetext{
${ }^{18}$ Vid. Zaffaroni, Alagia y Slokar, op. cit. nota 4, supra. p. 123.

${ }^{19}$ Disponible en: Gaceta de la Cámara de Senadores, LX/2PPO-176, jueves 13 de diciembre de 2007.

${ }^{20}$ Disponible en: Gaceta Parlamentaria de la Cámara de Diputados, Año XI, número 2401-VIII, martes 11 de diciembre de 2007 .
} 
3. Los delitos que no se sancionan con un marco punitivo específico elevado, pero que frente a la imposición acumulada de penas impuestas por la autoridad jurisdiccional, se incrementa la sentencia incluso a cientos de años ${ }^{21}$.

En cuanto al máximo de penas aplicables, el citado documento nos proporciona la siguiente información ${ }^{22}$ :

\begin{tabular}{|l|c|}
\hline \multicolumn{1}{|c|}{ Legislación } & Pena máxima de prisión \\
\hline Código Penal del Estado de Chihuahua. & Prisión vitalicia. \\
\hline Código Penal del Estado de México & Prisión vitalicia. \\
\hline Código Penal del Estado Libre y Soberano de Puebla & Prisión vitalicia. \\
\hline Código Penal para el Estado Libre y Soberano de Quintana Roo & Prisión vitalicia. \\
\hline Código Penal para el Estado Libre y Soberano de Veracruz de Ig- \\
nacio de la Llave
\end{tabular}

${ }^{21}$ Vid. Comisión Nacional de los Derechos Humanos (2016), Racionalización de la Pena de Prisión. Pronunciamiento, México, pp. 37 y 38.

${ }^{22}$ Ibídem, pp. 21 a 24.

Ciencia JuRÍdica. Departamento de Derecho. División de Derecho, Política y Gobierno, Universidad de Guanajuato - Año 6, No. 11, 2017 


\begin{tabular}{|c|c|}
\hline Código Penal para el Estado Libre y Soberano de Tlaxcala & 70 años. \\
\hline Código Penal del Estado de Guanajuato. & $\begin{array}{l}40 \text { años de manera general y } 70 \text { años para } \\
\text { feminicidio y concurso de delitos. }\end{array}$ \\
\hline Código Penal Federal. & $\begin{array}{l}60 \text { años, aunque se podrá incrementar si se } \\
\text { comete un nuevo delito en reclusión. }\end{array}$ \\
\hline Código de Justicia Militar. & 60 años. \\
\hline Código Penal de Coahuila. & $\begin{array}{c}60 \text { años, pero puede ser mayor a la máxima en } \\
\text { concurso de delitos. }\end{array}$ \\
\hline Código Penal para el Estado Libre y Soberano de Guerrero & 60 años. \\
\hline Código Penal para el Estado de Nayarit & 60 años. \\
\hline Código Penal para el Estado de Nuevo León & 60 años. \\
\hline Código Penal para el Estado de Hidalgo. & $\begin{array}{c}50 \text { años de manera general y } 60 \text { años por con- } \\
\text { curso de delitos. }\end{array}$ \\
\hline Legislación Penal para el Estado de Aguascalientes. & 50 años. \\
\hline Código Penal para el Estado de Baja California. & 50 años. \\
\hline Código Penal para el Estado de Baja California Sur. & 50 años. \\
\hline Código Penal para el Estado de Colima. & 50 años. \\
\hline Código Penal para el Estado Libre y Soberano de Jalisco. & 50 años. \\
\hline Código Penal para el Estado de Querétaro & 50 años. \\
\hline Código Penal para el Estado de Sinaloa & 50 años. \\
\hline Código Penal del Estado de Sonora & 50 años. \\
\hline Código Penal para el Estado de Tabasco & 50 años. \\
\hline Código Penal para el Estado de Tamaulipas & 50 años. \\
\hline Código Penal para el Estado de Campeche. & 40 años. \\
\hline Código Penal para el Estado de Michoacán & 40 años. \\
\hline Código Penal del Estado de Yucatán & 40 años. \\
\hline $\begin{array}{l}\text { Ley General para Prevenir; Sancionar y Erradicar los Delitos en } \\
\text { Materia de Trata de Personas }\end{array}$ & 40 años. \\
\hline
\end{tabular}




\begin{tabular}{|l|c|}
\hline Ley Federal contra la Delincuencia Organizada. & 40 años. \\
\hline $\begin{array}{l}\text { Ley Federal para el Control de las Sustancias Químicas } \\
\text { Susceptibles de Desvío para la Fabricación de Armas Químicas. }\end{array}$ & 40 años. \\
\hline Código Penal para el Estado de Zacatecas & 30 años. \\
\hline Ley Federal de Armas de Fuego y Explosivos. & 30 años. \\
\hline
\end{tabular}

Ahora bien, la Ley Nacional de Ejecución Penal, expedida el 16 de junio de 2016, señala que las personas sentenciadas por los delitos de delincuencia organizada, secuestro y trata de personas, no gozaran de los beneficios de preliberación.

Ello significa que las penas más altas que se pudieran imponer por el delito de secuestro, que fluctúan entre los 80 y los 140 años de prisión, según la modalidad, constituyen una prisión vitalicia encubierta, ya que por sí solas rebasan la esperanza de vida promedio de los mexicanos, que, según cifras del Instituto Nacional de Estadística y Geografía (INEGI), son de 72.1 años para los hombres y de 77.5 para las mujeres (datos de 2015) ${ }^{23}$. Y esto sin considerar que la edad mínima de imputación es a los 18 años de edad y, bajo esa consideración, una pena superior a los 55 años de prisión en hombres y de 59 en mujeres, es ya una prisión vitalicia.

En cuanto a los delitos de delincuencia organizada y trata de personas, una pena de 40 años de prisión, puede ser también vitalicia, dependiendo de la edad del sentenciado, ya que arriba de 32 años en hombres y de 37 en mujeres, se supera la expectativa de vida promedio.

En cuanto al resto de los delitos, la Ley Nacional de Ejecución Penal señala que la libertad condicionada bajo supervisión con o sin monitoreo electrónico (artículos 136 y siguientes), procede una vez que se haya cumplido la mitad de la pena en delitos dolosos, mientras que la libertad anticipada, que extingue la pena de prisión y otorga libertad al sentenciado (artículos 141 y siguientes), opera cuando se haya cumplido el 70 por ciento de la pena en los delitos dolosos.

Estos beneficios, suponiendo que se cumplan los demás requisitos que exige la ley, parecen complicados de operar en Estados como Chiapas y Oaxaca, que tienen penas máximas de 110 y 105 años de prisión, respectivamente, pero sí podrían ser aplicables en las entidades federativas restantes, a condición de que se trate de personas que delinquieron en edades tempranas y puedan soportar largos periodos de reclusión.

Tocante al encadenamiento sucesivo de sanciones, el estudio de la CNDH señala que los Códigos penales de Baja California, Chiapas, Chihuahua, Colima, Distrito Federal (hoy Ciudad de México), Durango, Guerrero, Michoacán, Tabasco, Tlaxcala y Veracruz, expresamente disponen que las sentencias dictadas en diferentes procesos penales se compurgarán sucesivamente ${ }^{24}$.

A contrapartida, el Código Penal Federal, en su artículo 25, dispone la compurgación simultánea de sanciones, mientras que la Ley Nacional de Ejecución Penal, no toma una posturaal respecto, señalando solamente, en el artículo 106, tercer párrafo, que cuando para el cómputo se

\footnotetext{
${ }^{23}$ Vid. INEGI (2017), Esperanza de Vida. México 2015, [en línea], disponible en: http://cuentame.inegi.org.mx/poblacion/esperanza.aspx?tema $=P 23$ de enero.

${ }^{24}$ Vid: CNDH, op. cit. nota 21, p. 7.
} 
establezca el orden de compurgación de las penas impuestas en diversos procesos, se dará aviso al resto de los jueces.

Tocante a la prisión vitalicia, que según la Suprema Corte de Justicia de la Nación no constituye una pena inusitada ${ }^{25}$, no hay por el momento una salida para su revisión y obtención de beneficios, pero a inicios de 2016 la Primera Sala remitió al Pleno un proyecto que plantea su inconstitucionalidad ${ }^{26}$.

\section{Situación de la pena de prisión en Europa}

En Europa la pena máxima de prisión no suele ser excesiva. En el caso de Francia, no puede exceder los treinta años ${ }^{27}$; Italia la limita a una duración máxima de 24 años ${ }^{28}$; tratándose de España puede alcanzar los 40 años $^{29} \mathrm{y}$ en Alemania no puede exceder de 15 años $^{30}$.

Sin embargo, en estos países existe lo que se conoce como la prisión permanente revisable, que, como su nombre lo indica, es una prisión vitalicia sujeta a escrutinio.Este tipo de reclusión existe tambiénen el Reino Unido, Austria, Suiza y Dinamarca ${ }^{31}$.

En el caso de Francia, la prisión permanente revisable (détention criminelle à perpétuité) se aplica en un importante número de supuestos, entre los que podemos destacar el genocidio o la incitación pública a cometerlo (artículos 211-1 y 211-2 de su Código Penal); los crímenes contra la humanidad (artículos 212-1 a 212-3); los crímenes de guerra (artículos 461-4, 461-8, 461-9, 46121, 461-23 a 461-27, 461-29 a 461-30); el homicidio premeditado (artículo 221-3) o acompañado de otro crimen o para preparar o facilitar un delito o favorecer la fuga o asegurar la impunidad del autor (artículo 221-2); el homicidio de un menor de 15 años, de un ascendiente, descen-

\footnotetext{
${ }^{25}$ Parece oportuno mencionar que en el año 2001, el pleno de la Suprema Corte de Justicia de la Nación, aprobó una tesis jurisprudencial en el sentido de que la prisión vitalicia constituía una pena inusitada, de las prohibidas por el artículo 22 constitucional, jurisprudencia que, en el año 2006 y en el marco de diversas extradiciones a los Estados Unidos, fue modificada para señalar lo contario, lo que, a mi parecer, es una infortuna interpretación. Sobre este particular, pueden verse las tesis de jurisprudencia bajo los siguientes rubros: Tesis: P./J. 127/2001, Semanario Judicial de la Federación y su Gaceta, Novena Época, t. XIV, octubre de 2001, p.15. PRISIÓN VITALICIA. CONSTITUYE UNA PENA INUSITADA DE LAS PROHIBIDAS POR EL ARTÍCULO 22 CONSTITUCIONAL./ Tesis: P./J. 2/2006, Semanario Judicial de la Federación y su Gaceta, Novena Época, t. XXIII, febrero de 2006, p. 5. EXTRADICIÓN. LA PRISIÓN VITALICIA NO CONSTITUYE UNA PENA INUSITADA DE LAS PROHIBIDAS POR EL ARTÍCULO 22 DE LA CONSTITUCIÓN POLÍTICA DE LOS ESTADOS UNIDOS MEXICANOS, POR LO QUE CUANDO AQUÉLLA SE SOLICITA ES INNECESARIO QUE EL ESTADO REQUIRENTE SE COMPROMETA A NO APLICARLA O A IMPONER UNA MENOR QUE FIJE SU LEGISLACIÓN./Tesis: P./J. 1/2006, Semanario Judicial de la Federación y su Gaceta, Novena Época, t. XXIII, febrero de 2006, p. 6. PRISIÓN VITALICIA. NO CONSTITUYE UNA PENA INUSITADA DE LAS PROHIBIDAS POR EL ARTÍCULO 22 DE LA CONSTITUCIÓN POLÍTICA DE LOS ESTADOS UNIDOS MEXICANOS.

${ }^{26}$ Al respecto véase la nota de Víctor Fuentes (2016), "Plantean suprimir la prisión vitalicia", en: Periódico Reforma, Ciudad de México, 22 de febrero, [en línea], disponible en: http://www.reforma.com/aplicacioneslibre/ artículo/default.aspx?id=773991\& md5=8e4d93fea8b7632f95ae756od9873382\&ta=odfdbac11765226904c16cb9ad1b2e fe 23 de enero de 2017.

27 Así el artículo 131-1 del Código Penal Francés (Code Pénal), [en línea], disponible en: https://www.legifrance. gouv.fr/affichCode.do?cidTexte=LEGITEXTooooo60707192 de febrero de 2017.

${ }^{28}$ Vid. El artículo 23 del Código Penal Italiano (Codice Penale), [en línea] disponible en: http://www.diritto.it/ codici/2 2 de febrero de 2017

29 Vid. El artículo 76 del Código Penal Español, [en línea], disponible en: https://www.boe.es/buscar/act. php?id=BOE-A-1995-254442 de febrero de 2017

${ }^{30}$ Vid. El artículo 38 (2) del Código Penal Alemán [Strafgesetzbuch (StGB)], [en línea], disponible en: http://www. gesetze-im-internet.de/bundesrecht/stgb/gesamt.pdf2 de febrero de 2017

${ }^{31} \mathrm{Al}$ respecto, véase la nota de Villanueva, Nati (2015) "Siete países de la UE regulan la prisión permanente revisable", en Diario ABC España, 23 de enero de 2015, [en línea], disponible en: http://www.abc.es/espana/20150123/ abci-paises-prision-permanente-201501222224.html, [consultado el] 5 de febrero de 2017.
} 
diente, cónyuge o concubino, de una persona particularmente vulnerable, en contra de ciertas autoridades o en razón de la orientación sexual dela víctima o de su pertenencia a una etnia, nación, raza o religión y el homicidio cometido por personas que actúen en una banda organizada (artículo 221-4); la desaparición forzada de personas (artículos 221-12 y 41-6); la tortura con resultado muerte (artículo 222-6); la violación acompañada o precedida de tortura (222-26); el secuestro de un menor de 15 años o acompañado o precedido de torturas que causen la muerte (artículos 224-2 y 224-5); el dirigir una organización criminal dedicada al terrorismo o al tráfico de estupefacientes (artículo 222-34); actos terroristas con resultado muerte (artículo 421-4); el secuestro de un aeronave, navío u otro medio de transporte, cuando se acompañe de actos de tortura o barbarie que causen la muerte de una o varias personas (artículo 224-6); la trata de personas recurriendo a la tortura o actos de barbarie (artículo 225-4-4); el proxenetismo recurriendo a la tortura o actos de barbarie (artículo 225-9); el robo acompañado o precedido de violencia que causen la muerte (artículo 311-10); la extorsión por banda organizada si se comete mediante la amenaza de una arma o portándola (artículo 312-6); la extorsión por banda organizada acompañada de violencia que cause la muerte o de tortura o actos de barbarie (artículo 312-7); el entregar a un nación o persona extranjera parte o la totalidad del territorio nacional (artículo 411-2); y el dirigir un movimiento de insurrección (artículo 412-6).

De conformidad con el artículo 132-23 del Código Penal Francés, los sentenciados a prisión perpetua, deben cumplir con un periodo de seguridad antes de poder solicitar cualquier tipo de beneficio. Este periodo es normalmente de 18 años, pero puede aumentarse hasta 22, si la Corte de apelación o el Tribunal así lo estiman conveniente, mediante una decisión especial.

En los casos previstos en el artículo 221-4 (homicidio con agravantes especiales) y condenas por actos de terrorismo, el periodo de seguridad puede llegar incluso hasta 30 años, si así lo decide la Corte de Apelación por una decisión especial ${ }^{32}$.

Manuel Jaén Vallejo apunta que una vez que la condena a perpetuidad es objeto de revisión, ha de pasar por varias fases, como la de un período de observación de hasta un año, siendo sometido el condenado a exámenes, entrevistas, etcétera, un régimen de semilibertad (como un tercer grado) de hasta dos años y una libertad vigilada hasta un máximo de cinco años ${ }^{33}$.

Ahora bien, pese al importante número de delitos amenazados con detención criminal a perpetuidad, el número de condenados no es realmente significativo, pues de los 60,742 sentenciados existentes en Francia en enero de 2015, sólo 139 lo eran a perpetuidad ${ }^{34}$.

Tocante a Italia, la prisión permanente revisable (ergastolo), se aplica en los casos de homicidio contra un ascendiente o descendente, el cometido por medio de veneno u otros medios insidiosos, con premeditación, por motivos aviesos o fútiles, para asegurar u ocultar otro delito, el producto del mismo o la impunidad del delincuente o después de haber cometido tortura o crueldad contra la persona (artículos 576 y 577 de su Código Penal); el secuestro con resultado muerte (artículos 289 bis, 605 y 630); el atentado terrorista con resultado muerte (artículo 280); ocasionar una epidemia mediante la difusión de gérmenes patógenos (artículo 438); el envenenamiento de agua o alimentos con resultado muerte (artículo 439); el atentado contra el Presidente de la República o el Jefe de Estado (artículos 276 y 295); los actos tendientes a reali-

\footnotetext{
${ }^{32}$ Vid. Los artículos 221-4, último párrafo, y 421-7, del Código Penal Francés, op cit. nota 27.

${ }^{33}$ Vid. JaÉn VAllejo, Manuel (2013), "Prisión permanente revisable”, en: Revista El Cronista del Estado Social y Democrático de Derecho, España, núm. 35, p. 5, [en línea], disponible en: http://www.iustel.com/diario_del_derecho/ noticia.asp?ref_iustel $=1115925,20$ de febrero de 2017.

${ }^{34}$ Vid. Ministère de la Justice, Les chiffres-clés de la Justice, France, 2016, p. 28, [en línea],o disponible en: http:// www.justice.gouv.fr/art_pix/stat_CC\%202016.pdf 13 de febrero de 2017.
} 
zar una masacre con resultado muerte (artículo 422), así como 9conductas relacionadas con la seguridad del Estado (artículos 242, 243, 244, 258, 261, 265, 284, 286, 287).

El artículo 176 del Código Penal Italiano señala que el condenado a pena de prisión, que durante el tiempo de ejecución de la pena haya tenido un comportamiento tal que lleve a considerar seguro su arrepentimiento, puede ser aceptado para la liberación condicional, agregando que en los casos de condenados a ergastolo (prisión perpetua), el beneficio sólo podrá otorgarse cuando hayan transcurrido al menos 26 años de la pena. Asimismo, la concesión de la libertad condicional está subordinada al cumplimiento de las obligaciones civiles derivadas del delito, salvo que el condenado demuestre tener imposibilidad para hacerlo.

En el caso de España, la prisión permanente revisable procede en los casos de asesinato (homicidio calificado) cuando la víctima sea menor de 16 años o sea especialmente vulnerable por razón de edad, enfermedad o discapacidad, que fuera subsiguiente a un delito contra la libertad sexual, sea cometido por quien pertenece a un grupo u organización criminal o se haya asesinado a más de dos personas (artículo 140 del Código Penal); se trate del homicidio del Rey, la Reina o el Príncipe o la Princesa de Asturias (artículo 485); el homicidio de un Jefe de Estado extranjero u otra persona internacionalmente protegida (artículo 605); el genocidio implicando homicidio, agrediendo sexualmente a la víctima o causándole lesiones que produzcan la inutilidad de un órgano o miembro principal o de un sentido, la impotencia, esterilidad, grave deformidad o mutilación genital (artículo 607); y los delitos de lesa humanidad si causaren la muerte de una persona (artículo 607 bis).

El artículo 92 del Código Penal Español (CPE) establece, como regla general, que el tribunal acordará la suspensión de la ejecución de la pena de prisión permanente revisable cuando se cumplan los siguientes requisitos: a) que el penado haya cumplido veinticinco años de su condena; b) que se encuentre clasificado en tercer grado 35 y c) que el tribunal, a la vista de la personalidad del penado, sus antecedentes, las circunstancias del delito cometido, la relevancia de los bienes jurídicos que podrían verse afectados por una reiteración en el delito, su conducta durante el cumplimiento de la pena, sus circunstancias familiares y sociales y los efectos que quepa esperar de la propia suspensión de la ejecución y del cumplimiento de las medidas que fueren impuestas, pueda fundar, previa valoración de los informes de evolución remitidos por el centro penitenciario y por aquellos especialistas que el propio tribunal determine, la existencia de un pronóstico favorable de reinserción social.

No obstante, el artículo 78 bis del CPE establece excepciones importantes cuando el sujeto haya sido condenado por dos o más delitos y, al menos, uno de ellos esté castigado por la ley con

\footnotetext{
${ }^{35}$ El artículo 36.1, segundo párrafo, del CPE, señala que la clasificación del condenado en el tercer grado deberá ser autorizada por el tribunal previo pronóstico individualizado y favorable de reinserción social, oídos el Ministerio Fiscal e Instituciones Penitenciarias. La clasificación a tercer grado puede hacerse, en lo general, a partir de los quince años de internamiento, salvo que se trate de delitos de terrorismo, en que será a los veinte. Sin embargo, el artículo 78 bis aumenta los plazos para ser clasificado en tercer grado, cuando hay concurrencia de dos o más delitos y, al menos, uno de ellos esté sancionado con pena de prisión permanente revisable. En estos casos, los plazos se aumentan en un término mínimo de 18 años a un máximo de 32 años en delitos de terrorismo.
} 
pena de prisión permanente revisable. En esos casos, para la revisión puede exigirse que hayan pasado veintiocho ${ }^{36}$, treinta ${ }^{37}$ o hasta treinta y cinco años38 de internamiento.

En Alemania, la prisión permanente revisable (lebenslange Freiheitsstrafe), se aplica de manera absoluta en los casos de asesinato (homicidio calificado) (artículo 211 del Código Penal); homicidio especialmente grave (artículo 212) y robo con violencia de un conductor o pasajero con resultado muerte (artículo 316 a); asimismo, conforme a la Ley de Introducción del Código Penal Internacional ${ }^{39}$, se aplica en los casos de genocidio con resultado muerte (artículo 6); crímenes contra la humanidad cometidos con la intención de destruir parcial o totalmente a una población o con resultado muerte (artículo 7); y crímenes de guerra cuando tengan por resultado la muerte de una persona protegida por el derecho internacional humanitario (artículo 8).

Se sancionan con prisión permanente o una pena que por lo general no puede ser inferior a 10 años de prisión, los casos de alta traición contra la federación (artículo 81 del Código Penal); traición a la patria especialmente grave (artículo 94); espionaje del servicio secreto especialmente grave (artículo 99); abuso sexual de niños con resultado letal (artículo 176 b); acceso carnal violento y violación con resultado muerte (artículo 178); secuestro extorsivo seguido de muerte de la víctima (artículo 239 a); robo con resultado muerte (artículo 251); incendio con consecuencia de muerte (artículo 306 c); provocación de una explosión nuclear causando muerte (artículo 307); provocación de una explosión detonante causando muerte (artículo 308); abuso de radiaciones ionizantes con resultado letal (artículo 309); y ataques al transporte aéreo o marítimo con resultado muerte (artículo $316 \mathrm{c}$ ).

Respecto a la revisión de la prisión permanente, el Código Penal Alemán dispone en su artículo 57a, que el tribunal suspenderá la ejecución del resto de la pena privativa de la libertad perpetua, para conceder la libertad condicional, cuando: a) se hayan cumplido quince años de la pena, b) la especial gravedad de la culpa del condenado no imponga el ulterior cumplimiento y c) se cumplan los presupuestos del artículo 57, inciso 1, frase 1, numerales 2 y 3; es decir, se justifique esto en consideración al interés de seguridad de la comunidad y el condenado de su consentimiento.

Asimismo, es aplicable, en lo conducente, el artículo 57, inciso 1, frase 2, el cual señala que en la decisión se deberá tener en cuenta particularmente la personalidad del condenado, sus antecedentes, las circunstancias de su hecho, el valor del bien jurídico amenazado en caso de reincidencia, la conducta del condenado en la ejecución, sus condiciones de vida y los efectos que para él se esperan de la suspensión.

Como puede verse, una prisión de por vida puede ser revisada a partir de los quince años de internamiento y, de acuerdo con Muñoz Conde, la regulación alemana hace que en la práctica sean pocos los condenados a cadena perpetua que pasen en prisión más de veinte años ${ }^{40}$.

De conformidad con la Corte Europea de Derechos Humanos, la prisión permanente revisable es compatible con la Convención Europea de Derechos Humanos y no viola el artículo $3^{\circ}$ de

\footnotetext{
${ }^{36}$ Caso de delitos de terrorismo, cuando concurra pena de prisión permanente revisable y el resto de las penas impuestas sumen un total que exceda de quince años.

${ }^{37}$ Caso de delitos ordinarios, cuando concurra pena de prisión permanente revisable y el resto de las penas impuestas sumen un total de veinticinco años o más.

${ }^{38}$ Caso de delitos de terrorismo, cuando concurra pena de prisión permanente revisable y el resto de las penas impuestas sumen un total de veinticinco años o más.

${ }^{39}$ Véase la Ley de Introducción del Código Penal Internacional (Alemania), [en línea], disponible en: $h t t p s: / / w w w$. mpicc.de/files/pdf1/vstgblspan1.pdf2o de febrero de 2017.

40 Muñoz Conde, Francisco (2011), “El Derecho Penal en Tiempos de Cólera”, en: Núñez Paz, Miguel Ángel (editor y coordinador), Un Derecho Penal comprometido. Libro homenaje al Prof. Dr. D. Gerardo Landrove Díaz. Valencia, España, Editorial Tirant lo Blanch, p. 874.
} 
la Convención, el cual prohíbe los tratos inhumanos o degradantes, siempre y cuando existan disposiciones claras sobre el plazo que debe transcurrir para que una persona pueda solicitar la revisión de su condena, a efecto de que la autoridad nacional pueda examinar si los cambios en el prisionero son significativos y si un proceso de rehabilitación se ha hecho en el curso de la sentencia, de tal modo que la continuación de su detención ya no pueda justificarse por motivos penológicos legítimos. Si bien la Corte señala que, atendiendo a la autonomía de los Estados, no le corresponde determinar el plazo en que deberá darse esa revisión, señala que, de acuerdo a la legislación comparada, este no debería exceder de los 25 años, con revisiones periódicas posteriores $^{41}$.

Desde mi punto de vista, esta interpretación es sólo parcialmente aceptable, pues aunque la prisión vitalicia puede ser revisada, queda latente la posibilidad de que el beneficio de excarcelación anticipada no se conceda nunca o se conceda después de un excesivo periodo, lo que la convertiría en un trato inhumano o degradante.

\section{Las penas de prisión en el Estatuto de Roma de la Corte Penal Internacional}

El Estatuto de Roma de la Corte Penal Internacional, vigente a partir de 2002, establece su competencia complementaria para conocer de los crímenes más graves de trascendencia internacional (artículo 1), mismos que son definidos como: a) el genocidio (artículo 6); b) los crímenes de lesa humanidad; c) los crímenes de guerra (artículo 8); y el crimen de agresión (artículo 8 bis).

No habremos de abundar aquí sobre los elementos típicos correspondientes a cada delito, ni a los requisitos para que la Corte pueda aceptar su competencia, pero si habremos de hacer hincapié en que se trata de los crímenes más graves en contra del género humano.

De acuerdo con el artículo 77 del Estatuto, la Corte podrá imponer a la persona declarada culpable de uno de los crímenes anteriores una de las penas siguientes: a) la reclusión por un número determinado de años que no exceda de 30; o b) la reclusión a perpetuidad cuando lo justifiquen la extrema gravedad del crimen y las circunstancias personales del condenado.

Por su parte, el artículo 110 señala que cuando el recluso haya cumplido las dos terceras partes de la pena o 25 años de prisión en caso de cadena perpetua, la Corte examinará la sanción para determinar si ésta puede reducirse. Al proceder al examen, la Corte podrá reducir la pena si considera que concurren uno o más de los siguientes factores: a) si el recluso ha manifestado desde el principio y de manera continua su voluntad de cooperar con la Corte en sus investigaciones y enjuiciamientos; b) si el recluso ha facilitado de manera espontánea la ejecución de las decisiones y órdenes de la Corte en otros casos, en particular ayudando a ésta en la localización de los bienes sobre los que recaigan las multas, las órdenes de decomiso o de reparación que puedan usarse en beneficio de las víctimas; y c) otros factores indicados en las Reglas de Proce-

\footnotetext{
${ }^{41}$ Sobre el particular véase: Case of Hutchinson v. The United Kingdom (Application no. 57592/o8), 3 February 2015, European Court of Human Rights, párrafo 20, [en línea], disponible en: http://hudoc.echr.coe.int/ eng\#\{,itemid“:[,oo1-150778“]\} 5 de febrero de 2017.
} 
dimiento y Prueba que permitan determinar un cambio en las circunstancias suficientemente claro e importante como para justificar la reducción de la pena ${ }^{42}$.

Si la Corte en su examen inicial, determina que no procede reducir la pena, volverá a examinar la cuestión con la periodicidad y con arreglo a los criterios indicados en las Reglas de Procedimiento y Prueba ${ }^{43}$.

\section{Conclusiones}

Las elevadas sanciones penales que pueden imponerse en nuestro país, particularmente la prisión vitalicia y las penas que superan la expectativa de vida de una persona, son demostrativas de la creencia excesiva en la teoría de la prevención general negativa a la hora de legislar.

Se trata de un populismo penal que -ante el incremento de la percepción de inseguridad por parte de la población y el recrudecimiento de los fenómenos delictivos-, hace aparecer que la autoridad realiza acciones "rápidas y eficientes" que, fundamentalmente, incrementan las penas corporales de quienes cometen un delito y magnifican los resultados de los operativos de las fuerzas del orden para demostrar que sí se está atendiendo el problema ${ }^{44}$.

Sin embargo, ello no resuelve el fondo del asunto, pues en realidad lo que se requiere no es que las penas se aumenten, sino que éstas, aunque cortas, verdaderamente se apliquen, lo que no ocurre en nuestro país, donde los índices de impunidad son muy altos. De acuerdo con los datos del INEGI, la cifra negra en el año 2015 (delitos no denunciados o que habiéndose denunciado no se inició investigación) alcanzó el 93.7\% 45, lo que quiere decir que autoridad sólo conoce del $6.3 \%$ de los delitos que son cometidos en el país, lo que representa un porcentaje mínimo. De ahí que un aparato de investigación y sanción tan deficiente no disuada, dada la escasa posibilidad de que las penas, aunque elevadas, se apliquen.

Ahora bien, para aquellos pocos que el sistema de sanción penal logra captar, la pena de prisión vitalicia, las penas muy largas de prisión y/o que no admiten beneficio alguna en la fase ejecutiva o que se encadenan sucesivamente, representan la puesta en práctica de un sistema

\footnotetext{
${ }^{42}$ La Regla 223 señala que al examinar una reducción de la pena, los magistrados de la Sala de Apelaciones, además de los criterios enumerados en el artículo 110, consideraran adicionalmente los siguientes: a) la conducta del condenado durante su detención, que revele una auténtica disociación de su crimen; b) las posibilidades de reinsertar en la sociedad y reasentar exitosamente al condenado; c) si la liberación anticipada del condenado crearía una gran inestabilidad social; d) cualquier medida de importancia que haya tomado el condenado en beneficio de las víctimas, así como los efectos de una liberación anticipada sobre las víctimas y sus familias; y e) las circunstancias individuales del condenado, incluido el deterioro de su estado de salud física o mental o su edad avanzada.

${ }^{43}$ La Regla 224 señala que a los efectos de la aplicación del artículo 110, los magistrados examinarán la cuestión de la reducción de la pena cada tres años, a menos que indiquen un intervalo más breve en la decisión que adopten. De producirse un cambio significativo en las circunstancias, los magistrados podrán autorizar al condenado a pedir una revisión dentro de los tres años o del período más breve que hayan fijado.

${ }^{44}$ En este sentido: Vázquez del Mercado Almada, Guillermo (2011), "Populismo penal a la mexicana", Revista Letras Libres, Blog "Polifonía", 23 de junio, [en línea], disponible en: http://www.letraslibres.com/blogs/blog-dela-redaccion/populismo-penal-la-mexicana2 de febrero de 2014.

${ }^{45}$ Vid. INEGI (2017) Encuesta Nacional de Victimización y Percepción sobre Seguridad Pública (ENVIPE) 2016, México, Septiembre de 2016, [en línea], disponible en: https://www.google.com.mx/search?q=envipe+2015\&ie=utf$8 \triangleleft o e=u t f-8 \& c l i e n t=f i r e f o x-b-a b \triangleleft g f e \_r d=c r \& e i=R K b I W P W v B s 7 a 8 g e v 2 b n I C Q 20$ de febrero de 2017.
} 
que apuesta por la prevención especial negativa, es decir, por la neutralización del delincuente y su eliminación del cuerpo social por el tiempo que le reste de vida.

Y esta encarnizada respuesta desde luego que no es compatible con los principios de proporcionalidad y reinserción social de la pena que, según la Constitución, deben guiar su configuración.

De ahí la necesidad de establecer un mínimo de racionalidad para los máximos de pena de prisión a imponer en nuestro país. No podemos aspirar a tener replegados a todos los prisioneros, pues como dice Silva Sánchez, siguiendo a Schall/ Schreibauer, una sociedad que quiere mantenerse en un Derecho penal respetuoso con la individualidad y los derechos fundamentales de la persona, también del delincuente, una sociedad que, por tanto, quiere conceder a todo autor la posibilidad de la resocialización, debe también estar dispuesta necesariamente a soportar un riesgo para la seguridad de la colectividad ${ }^{46}$.

Pero ¿cuál ha de ser el límite máximo imponible en un marco de racionalidad? Para Ferrajoli, el límite máximo de la pena privativa de libertad, cualquiera que sea el delito cometido, debería ser de 10 años ${ }^{47}$. Mir Puig señala que hoy se pide que la pena privativa de libertad tenga un límite máximo de 15 años, aunque se trate de una aspiración no realizada en la mayoría de los países $^{48}$. Zaffaroni señala que la pena máxima no puede exceder de 30 años de prisión, toda vez que esa es la pena que el Estatuto de Roma de la Corte Penal Internacional impone por el delito más grave contra el género humano, que es el delito de genocidio ${ }^{49}$.

Las legislaciones europeas y el Estatuto de Roma de la Corte Penal Internacional, que, aunque, como vimos, pueden imponer la prisión vitalicia revisable, manejan penas máximas que van desde 15 hasta los 40 años de prisión.

Desde mi punto de vista, el tope máximo para la pena de prisión en México debería ser de 30 años, sin posibilidad de imponer prisión vitalicia.

30 años parece un plazo razonable y proporcional y que puede hacer viable, en algún momento dado, el ideal de reinserción social, sobre todo considerando que no debería haber prohibición para conceder beneficios preliberacionales en ningún supuesto. De esa manera y suponiendo que se cumplan los requisitos legales, una persona sentenciada a 30 años de prisión

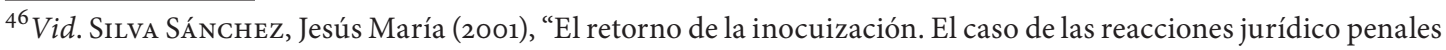
frente a los delincuentes sexuales violentos”, en: Arroyo Zapatero, Luis Alberto y Berdugo Gómez de la Torre, Ignacio, Homenaje al Doctor Marino Barbero Santos: in memoriam, España, Ediciones de la Universidad de Castilla - La Mancha y de la Universidad Salamanca, p. 710.

47 Ferrajoli, Luigi (2005), Derecho y razón. Teoría del garantismo penal, $7^{\text {a }}$ edición, Madrid, España, Editorial Trotta, p. 414.

${ }^{48}$ Vid. Mir Puig, op. cit. nota 2, p. 123.

${ }^{49}$ Falcone, Pablo (2014), entrevista a Eugenio Raúl Zaffaroni, publicada en el Diario La Capital de la Ciudad de Mar del Plata, Argentina, 21 de enero, [en línea], disponible en: http://www.lacapitalmdp.com/noticias/laciudad/2014/01/12/254024.htm, [consultado el 23 de febrero de 2017].
} 
podría ser candidata a la libertad condicionada bajo supervisión con o sin monitoreo electrónico a partir de los 15 años de internamiento y a la libertad anticipada luego de 21.

Asimismo, debería resolverse también la cuestión del compurgamiento sucesivo de sentencias dictadas en diferentes procesos, dando lugar a la compurgación simultánea, a fin de no hacer nugatorio el tope máximo fijado por la ley.

Se ve difícil, en el corto plazo, avanzar en la dirección propuesta, dada la dispersión de leyes penales en México y la ausencia de consensos para crear una codificación penal única.

Sin embargo, valdría la pena impulsar el proyecto de una ley general penal, que permita establecer las bases mínimas, principios y lineamientos generales para los Códigos Penales del país, entre ellos, la pena máxima aplicable.

$\mathrm{Al}$ respecto, hay que recordar que el Plan Nacional de Desarrollo 2013-2018, en el apartado dedicado al Sistema de Justicia Penal, señala que [...] para la implementación del Nuevo Sistema es necesario impulsar la expedición de un Código de Procedimientos Penales Único y una Ley General Penal, ya que la multiplicidad de normas dificulta la procuración y la impartición de justicia ${ }^{50}$.

Pero mientras esto sucede, podría avanzarse con las modificaciones legales que permitan que los casos de prisión vitalicia o de penas muy largas de prisión, puedan ser revisados después de un periodo de tiempo determinado, tal y como sucede en Europa con la prisión permanente.

$\mathrm{Al}$ respecto, la $\mathrm{CNDH}$ ha señalado que es preciso establecer un programa de prisión permanentemente revisable para aquellas personas sentenciadas con condenas superiores a los 30 años y en vitalicias, a fin de que se evalúe la pertinencia de la excarcelación bajo argumentos humanitarios, sobre el cumplimiento de programas de reinserción social efectiva y disminución de riesgo social, además de que deberá existir la posibilidad de aplicar beneficios de libertad anticipada a todo aquel interno que cumpla con su tratamiento de reinserción social, sin exclusión del derecho premial por tipo de delito ${ }^{51}$.

De establecerse estas medidas, estimo que es factible, por la vía de las leyes de ejecución penal, establecer un equilibrio con los principios de proporcionalidad y reinserción social de la pena y también contribuir al respecto a los derechos humanos y a la humanidad de las penas en México. Esperemos que pronto podamos avanzar hacia esa dirección.

\section{Fuentes de información}

\section{Bibliografía}

Ferrajoli, Luigi (2005), Derecho y razón. Teoría del garantismo penal, $7^{\text {a }}$ edición, Madrid, España, Editorial Trotta.

JaÉn VAllejo, Manuel (2013), “Prisión permanente revisable”, en: Revista El Cronista del Estado Social y Democrático de Derecho, España, núm. 35, [en línea], disponible en: http:// www.iustel.com/diario_del_derecho/noticia.asp?ref_iustel=1115925, [consultado el 20 de febrero de 2017].

Mir Puig, Santiago (2006), Derecho Penal. Parte General, 8ª edición, Barcelona, España, Editorial Reppertor.

\footnotetext{
${ }^{50}$ Gobierno de la República (2017), Plan Nacional de Desarrollo 2013-2018, México, p. 35, [en línea], disponible en: http://pnd.gob.mx/wp-content/uploads/2013/o5/PND.pdf, [consultado el 12 de marzo de 2017.]

${ }^{51}$ Vid. Comisión Nacional de los Derechos Humanos, op. cit. nota 21, pp. 54 y 70.
} 
Muñoz Conde, Francisco (1975), Introducción al Derecho Penal. España, Bosh Casa Editorial. (2011), "El Derecho Penal en Tiempos de Cólera”, en: Núñez Paz, Miguel Ángel (editor y coordinador), Un Derecho Penal comprometido. Libro homenaje al Prof. Dr. D. Gerardo Landrove Díaz. Valencia, España, Editorial Tirant lo Blanch.

Jаковs, Günther (1991), Derecho Penal: Parte General. Fundamentos y Teoría de la Imputación, Traducción de la $2^{\mathrm{a}}$ edición alemana de 1991 por Joaquín Cuello Contreras y José Luis Serrano González de Murillo, Madrid, Marcial Pons, Ediciones Jurídicas.

Roxin, Claus (1994), Derecho Penal: Parte General. Tomo I. Fundamentos. La Estructura de la Teoría del Delito, Traducción de la $2^{\mathrm{a}}$ edición alemana de 1994 y notas por DiegoManuel Luzón Peña, Miguel Díaz y García Conlledo y Javier de Vicente Remesal, Madrid, Editorial Civitas.

(1976), "Sentido y Límites de la Pena Estatal", en: Problemas Básicos del Derecho Penal, Trad. del alemán y notas por Diego Manuel Luzón Peña, Madrid, Editorial Reus.

SiLva SáncheZ, Jesús-María (2001), "El retorno de la inocuización. El caso de las reacciones jurídico penales frente a los delincuentes sexuales violentos", en: ARroyo ZAPATERo, Luis Alberto y Berdugo Gómez De La Torre, Ignacio, Homenaje al Doctor Marino Barbero Santos: in memoriam, España, Ediciones de la Universidad de Castilla-La Mancha y de la Universidad Salamanca.

(1992), Aproximación al Derecho Penal Contemporáneo, Barcelona, España, José María Bosch Editor.

Vázquez Del Mercado Almada, Guillermo (2011) "Populismo penal a la mexicana", en: Revista Letras Libres, Blog "Polifonía", 23 de junio, [en línea], disponible en: http://www. letraslibres.com/blogs/blog-de-la-redaccion/populismo-penal-la-mexicana, [consultado el 2 de febrero de 2014].

Villarreal Palos, Arturo (1987), "La Función de la Pena”, en: Criminalia, Órgano de la Academia Mexicana de Ciencias Penales, México, D.F., enero-diciembre, núms. 1-12, Editorial Porrúa.

Zaffaroni, Eugenio Raúl (200o), Alagia, Alejandro y Slokar, Alejandro, Derecho Penal: Parte General, Buenos Aires, Argentina, Editorial Ediar.

\section{Hemerográficas}

Fuentes, Víctor Fuentes (2016), "Plantean suprimir la prisión vitalicia”, en: Periódico Reforma, Ciudad de México, 22 de febrero, [en línea], disponible en: http://www.reforma.com/aplicacioneslibre/articulo/default.aspx?id=773991e $m d_{5}=8$ e 4 d93fea8b7632f95ae 7560 d9873382

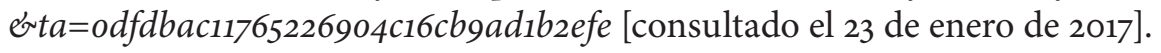

Villanueva, Nati (2015), "Siete países de la UE regulan la prisión permanente revisable", en: Diario ABC España, 23 de enero, [en línea], disponible en: $h t t p: / / w w w . a b c . e s / e s p a-$ 
na/20150123/abci-paises-prision-permanente201501222224.html, [consultado el 5 de febrero de 2017].

FAlcone, Pablo (2014) "Una condena a 50 años de prisión es una locura", entrevista a Eugenio Raúl Zaffaroni, en: Diario La Capital de la Ciudad de Mar del Plata, Argentina, 21 de enero, [en línea], disponible en: http://www.lacapitalmdp.com/noticias/laciudad/2014/01/12/254024.htm, [consultado el 23 de febrero de 2017].

\section{Documentos}

CASE OF HUTCHINSON v. THE UNITED KINGDOM (Application no. 57592/o8), 3 February 2015, European Court of Human Rights, párrafo 20, http://hudoc.echr.coe.int/ eng\#\{“itemid”:[“oo1-150778”] 5 de febrero de 2017.

Comisión Nacional de los Derechos Humanos (2016), Racionalización de la Pena de Prisión. Pronunciamiento, México.

Dictamen de la Cámara de Senadores, Reforma Constitucional publicada en el Diario Oficial de la Federación el 18 de junio de 2008, en Gaceta de la Cámara de Senadores, LX/2PPO-176, jueves 13 de diciembre de 2007.

Dictamen de la Cámara de Diputados, Reforma Constitucional publicada en el Diario Oficial de la Federación el 18 de junio de 2008, en Gaceta Parlamentaria de la Cámara de Diputados, Año XI, número 2401-VIII, martes 11 de diciembre de 2007.

INEGI (2017), Esperanza de Vida. México 2015, [en línea], disponible en: http://cuentame.inegi. org. $m x$ /poblacion/esperanza.aspx?tema $=P 23$ de enero.

INEGI c(2017), Encuesta Nacional de Victimización y Percepción sobre Seguridad Pública (ENVIPE) 2016, México, Septiembre de 2016, https://www.google.com.mx/search?q=envipe+

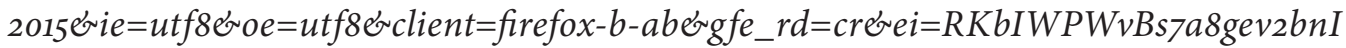
CQ20 de febrero.

Ministère De la Justice (2017), Les chiffres-clés de la Justice, France, 2016, p. 28, [en línea] disponible en: http://www.justice.gouv.fr/art_pix/stat_CC\%202016.pdf 13 de febrero.

Gobierno de la República, Plan Nacional de Desarrollo 2013-2018, México, [en línea] disponible en: $h t t p: / / p n d . g o b . m x / w p$-content/uploads/2013/05/PND.pdf, [consultado el 12 de marzo de 2017].

\section{Legislación comparada}

Código Penal Alemán [Strafgesetzbuch (StGB)], [en linea], disponible en: http://www.gesetzeim-internet.de/bundesrecht/stgb/gesamt.pdf, [consultado el 2 de febrero de 2017].

Código Penal Español, https://www.boe.es/buscar/act.php?id=BOE-A-1995-254442 de febrero de 2017. 
Código Penal Francés (CodePénal), [en línea], disponible en: https://www.legifrance.gouv.fr/ affichCode.do?cidTexte=LEGITEXTooooo6070719, [consultado el 2 de febrero de 2017].

Código Penal Italiano (Codice Penale), [en línea], disponible en: http://www.diritto.it/codici/, [consultado el 22 de febrero de 2017].

Ley de Introducción del Código Penal Internacional (Alemania), [en línea], disponible en: https://www.mpicc.de/files/pdf1/vstgblspan1.pdf, [consultado el 20 de febrero de 2017]. 